The Social Sciences 5 (2): 70-75, 2010

ISSN: $1818-5800$

(C) Medwell Journals, 2010

\title{
Managing Organizational Culture for Effective Communication
}

\author{
Solomon George Anaeto \\ Department of Mass Communication, Babcock University, Ilisan-Remo, Ogun State, Nigeria
}

\begin{abstract}
When the organizational culture is well managed, effective communication is enhance and when effective communication is applied, the organization's goals and objectives become achievable. On this premise, this study looks at the organizational culture (which may be internally or externally induced) which accounts for the uniqueness of each organization. The culture, in turn, defines the operations in the organization. In addition, the organizational goals and objectives act as the propeller of the culture-moving the whole organization towards a definite direction. The study also discusses the role of managers as cosmopolites in organizations who often interact with the external environment. They come in introducing new ideas to enrich the organizational culture or to prune the existing ones for better productive values and beliefs. Hence, this study is also concerned with how to manage organizational culture for effective organizational communication.
\end{abstract}

Key words: Organizational culture, communication, goals, objectives, environment

\section{INTRODUCTION}

An organization consists of synergistic, interrelated and inter-dependent parts. Soola (2000) noted that organizations are usually created by and for people who share certain characteristics, aspirations and goals in common. The structure of an organization is deliberate and constructed where and when an individual or group has objective that cannot be pursued, attained or sustained without the input of other individuals or groups.

According to Beckhard (1969), an effective organization is one in which the total organization, the significant subparts and individuals, manage their research against goals and plans for the achievement of these goals. The organization and its parts see themselves as interacting with each other and a larger environment. The organization is an open system. And there is a shared value and management strategy to support it, of trying to help each person (or unit) in the organization maintain his (or its) integrity and uniqueness in an interdependent environment.

Organizational objectives and goals: The importance of an organization having a clearly defined objectives cannot be over-emphasized. The objectives give direction and purpose to an organization.

The sub-units of an organization are bound together by the common objectives and this helps to bring meaning into the interrelatedness of the different sub-units activities. Therefore, it goes without saying that the success of an organization, to an extent is dependent on a well-spelt out objectives.
Kast and Rosenzweig (1974) declared that formal organizations are contrived social system designed to accomplish specific purposes. You may call these purposes the goals of the organization. And the goals of an organization have an important influence on its interaction with the environmental supra system as well as the other sub-systems (Fig. 1).

Kast and Rosenzweig (1974) also stated that goals focus the attention of participants upon actions which are organizationally relevant. Goals help to determine the technologies required and also set the basis for specialization of efforts, authority patterns, communication and decision networks and other structured relationships.

Organizational values: Kast and Rosenzweig (1974) state organizational values as those values which are held by the organization which represent a composite of individual, group, total organization and cultural inputs. Organizations depend on a minimum level of shared values among internal participants and the external sources for the existence. It should be understood that deeply ingrained cultural values provide a measure of cohesiveness.

Every human participant brings a certain set of values to the organization. Value input also comes from a wide variety of external sources-customers, competitors, suppliers (Kast and Rosenzweig, 1974).

The dynamic nature of organizations: Soola (2000) opined that a static organization is a misnomer, as organizations must be dynamic to continue to be relevant. Each organization has its unique characteristics in terms 


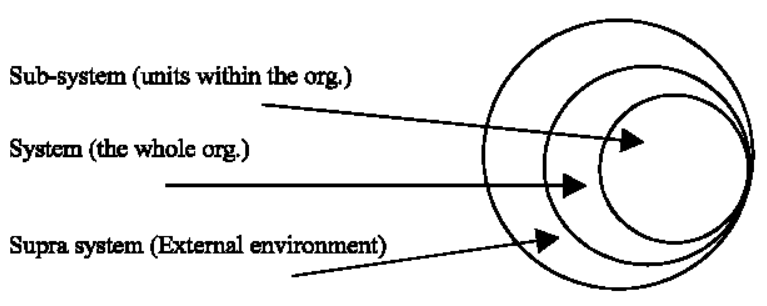

Fig. 1: Organization as a system Allen (1977). Organizational management through communication

of structure, objectives and mode of operations. Organizations change in response to changing economy, politics, culture and technology.

Under the change management model and approaches, Carr et al. (1996) stated that Caught in the vortex of fierce global competition and the ever increasing speed of new technology, organizations find themselves in a situation where they can survive only by adopting and adapting fast.

Deep organizational changes have a profound impact on people within organizations. In fact, today most businesses have accepted the notion that the only thing constant is change. Non-stop change is often referred to as white water turbulence, forcing most leaders to examine the very essence of their organizations (Beckhard and Pritchard, 1992) (Fig. 2).

Characteristics of an organization: Organizations can be divided into two: formal and informal. Informal organizations emerge spontaneously whenever people interact with one another, e.g., spectators in a boxing tournament. On the other hand, the formal organizations are made up of a group/groups of people whose activities are consciously coordinated towards common objectives (Fig. 3).

Soola and Ayoade (2000) saying that an organization has the following in varying degrees and combinations:

- An interdependence or interlocking activities

- Role specifications for members who occupy positions

- A division of labour and varying degrees of job specifications

- Status hierarchy which exists as a coordinating and controlling mechanism

- A dynamic system which is in a constant state of flux

- A system of processing various inputs to produce various outputs

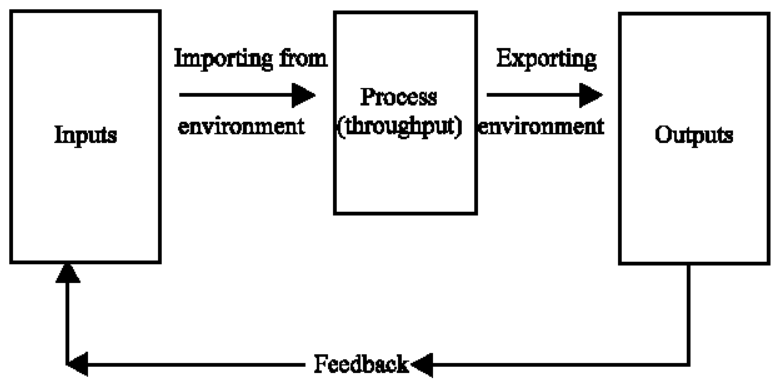

Fig. 2: Organization as an open system

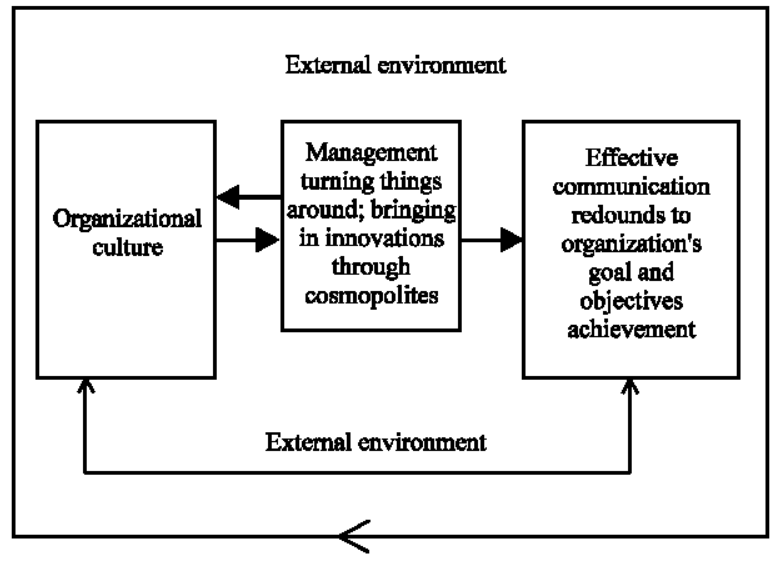

Fig. 3: Conceptual framework

- A communication network or more accurately, a network of networks

- A combination of individual and groups-a group of groups

Defining culture: McQuail (2005) defined culture as a process but that it can also refer to some shared attributes of a human group such as their physical environment, tools, religion, customs and practices or their whole way of life. Culture can also refer to texts and symbolic artefacts that are encoded with particular meanings by and for people with particular cultural identifications.

Culture is a set of important assumptions (often unstated) that members of a community share (Sathe, 1983). A focus on culture, according to Smircich (1985), helps us focus on the assumptions that drive the way things are done in the organizations. And Nellen (1997) noted that culture is a basic pattern of assumptions that has worked well enough to be considered valid and therefore, to be taught to new members as the correct way to perceive, think and feel in relation to problems.

Finally, Pepper (1995) stated that organizations are cultures constructed through the communication (verbal and nonverbal language use) of organization members. 
Culture can be explained and defined in so many different ways. However, as noted by Barnett (1988) despite some definitional variations, cultural research is tied together by the assumption that the language of the organization member is the key to understanding the organizational culture. A cultural approach to organization then is a language approach. By examining the language of organizations members as presented in the various message forms available, the cultural researcher is able to infer to the level of member beliefs and assumptions (Bantz, 1993).

McQuail (2005) has drawn some characteristics of culture thus:

- Collectively formed and held and shared with others

- Open to symbolic expression

- Ordered and differentially valued

- Systematically patterned

- Dynamic and changing

- Spatially located

- Communicable over time and space

From this, we can understand that culture has different usages. And one of the essential attributes of culture is communication. Hence, it is difficult for culture to develop, survive, extend and generally succeed without communication.

It follows therefore that when we talk of an organizational culture, we are looking at what is happening in the organization in terms of communication.

\section{Dynamic and changing nature of organizational culture:} Some of the attributes of culture are dynamism and change. McQuail (2005) says that culture lives and changes, has a history and potentially a future. Culture is seen as having a dynamic continuity over a time. Therefore, organizational culture lends itself to the same dynamics and change-depending on the catalyst that comes into the organization's culture.

The term organizational culture might lead to the mistake of thinking that organizations have one primary or dominant culture. However, researchers such as Corad (1994) and Pepper (1995) argue that organizational cultures are dynamic.

\section{MANAGING ORGANIZATIONAL CULTURE}

The organizational culture can be managed by using the organizational development strategies and models. Organizational development achieves its goals through planned interventions using behavioural-science knowledge. A strategy is developed of intervening or moving into existing organization and help it, in effect, stop the music examine its present ways of research, norms and values and look at alternative ways of working or relating or rewarding (Berkhard, 1969).

Some characteristics of Organization-Development (OD) efforts: Berkhard (1969) stated that most successful organization development efforts have the following characteristics:

- There is planned programme involving the whole system

- The top of the organization is aware of and committed to the program and to the management of it

- It is related to the organization's mission

- It is a long-term effort. At least two or three years is required for any large organizational change to take effect and be maintained

- Activities are action-oriented. The types of interventions and activities in which organization members participate are aimed at changing something after the activity

- It focuses on changing attitudes and/or behaviour. The major target of change is the attitudes or behaviour and performance of people in the organization

- It usually relied on some form of experience-based learning activities. The reason for this is that if a goal is to change attitudes and/or behaviour, a particular type of learning situation is required for such change to occur

- OD efforts work primarily with groups. An underlying assumption is that groups and teams are the basic units of organization to be changed or modified as one moves toward organization health and effectiveness

When an organization decides to make a strategic change, there is a planning process that results to implementation. It might be changing the way, research is done as in reengineering or changing reporting relationships through restructuring or downsizing (Timony, 2001). Thus, successful change efforts can yield high productivity with reduced cost and job security.

\section{MANAGERS AS COSMOPOLITES}

Managers are cosmopolites in organizations. The cosmopolite tends to travel more and forms contacts 
outside the organization with government agencies, other organizations, associations, etc. The cosmopolite channels new information into the organization from outside. They draw meaning from multiple sources outside the organization and then graft new ideas and knowledge onto the existing organization's culture (The Institute for Working Futures, 2005).

Jeffres et al. (2004) notes that people who are more cosmopolitan are earlier adopters of innovation, know more about an innovation and exert opinion leadership. They also are more likely to be stimulators of collective innovation-decisions, i.e., recognize that a need exists and call attention to it in a specific social system.

The manager as cosmopolite plays a variety of roles as change agent (teacher or consultants).

\section{THE MANAGER AS A COMMUNICATOR OF CHANGE}

Organizational change is as inevitable as communication itself. It has been said that change is the only thing that is constant in life. Therefore, the manager must learn the strategies to control communication at all levels to bring about necessary cultural changes in the organization.

Allen (1977) noted that the good management and good agents of change operate from the same set of assumptions which are:

- Change is an alteration of an existing field of forces

- Effective change is bringing about an alteration of these forces so as to reduce tension and gain commitment to ('ownership' of) change

- The effective change agent and manager accomplishes this by understanding the total array of forces operating on a particular equilibrium and reach consensus on a change strategy

- Consensus is built by obtaining as much participation and commitment as possible in the diagnosis and manipulation of the relevant forces

- Organizational cultures must be changed to reinforce and maintain changes achieved by individuals

RACE model of planning a change in an organization: RACE is the acronym for research, action, communication and evaluation. Relating this model to planning change in an organization.

Research: In carrying out the research the following questions in the book-Analysing Organizational Culture for Improved Productivity by the National Defence University (2006) could serve as a guide.
- How have the top leaders shaped the organization's culture in response to changes in the environment?

- What are the organization's underlying assumptions about itself and its people?

- What are the organization's stated values and operating values?

- Are the stated values and operating values consistent?

- What do key behaviours, including the behaviour of the top leaders, tell you about the organization's culture?

- What do the organization's structure and its information flow tell you about the organization's culture?

- What do the physical layout and appearance of the organization's physical facilities tell you about the culture?

- What do the organization's decision-making processes tell you about the organization's culture?

Action: These are strategies emanating from the initial research carried out which will be used in finding solutions to or in plugging the gaps existing in the organization's communication system. The following are the actions to be taken:

- Top leaders in the organization should introduce relevant cultural innovations

- Educate the organization members to embrace necessary changes

- The organization should come up with appropriate values

- $\quad$ Ensuring consistency between the stated values and the operating values

- Managers should behave in a manner that will show the organization's culture as good

- Organizational structures and information flow should be such that portray the organization's culture

- Physical layout and appearance of the organization's physical facilities should reflect the culture

- Organization's decision-making process should reflect the organization's culture in positive light

Communication: No action is meaningful without it being communicated to the stakeholders within and outside the organization. Therefore, the proper communication process should be adopted. This is with the view of ensuring an effective communication, which of course is goal-directed and would enhance the organization's productivity. 
The communication process has to be taken into consideration. All the elements of the communication process (source-which is the managers message the actions above; channel-memo, letters, bulletin board, etc.; receiver-employees; feedback-reactions from employees to the managers) has to be in tune with the actions above to achieve positive change in the organization.

Evaluation: Evaluation means assessing the actions adopted and the communication outcomes. The result of the evaluation might give rise to modification in any of these strategies applied. To this end, there has to be continuous monitoring and evaluation process built into the organization's communication system. Some important questions that should be considered are:

- Have the objectives of the exercise been achieved?

- Have we been able to bring about the desired change?

- Where did we fail?

- What strategy amendments should be introduced and how do we go about it?

Effective communication: Kolawole and Akinyele (2002) see communication as the flow of material, information, perception and understanding between various parts or members of an organization. Communication here involves all the methods, means and media of communication (communication technology); all the channels, networks and systems of communication (organizational structures) and all the person-to-person exchange (interpersonal communication). It includes all aspects of information flow either vertical, horizontal, diagonal or semi-vertical and various communication skills: writing, reading, speaking and listening.

Effective communication requires not merely the transmission of information but the sharing of a message and the meaning of the message. Effective communication fosters understanding of one another and brings people closer together (Maurus, 1996).

One goes into communication transaction for a purpose or expecting certain actions to occur. The success of such a communication transaction can, therefore, be measured with regards to whether the object of the communication has been achieved or not. In the same vein, effective communication is expected to bring about goals or objectives achievement in an organization.

De Witt (2004) stated that effective communication is a lot more than just giving people regular updates. People are naturally resistant to change and you have got to sell them the benefits of it. To communicate the changes, do what any good marketing manager would do: define segments and then develop key messages for each segment. The aim is to address their areas of concern. Ask for feedback, as this will help you to make the necessary adjustment for improvement.

\section{THE MANAGER AND EFFECTIVE COMMUNICATION}

Communication is very important to an organization not only to transmit information between individuals but also to ensure efficiency in all subunits in an organization. The job of the manager is to communicate effectively to persuade or motivate the researchers to bring about the desired change in the organization. Through strategically planned communication, both within and outside the organization, he seeks to achieve the organizational goals and objectives.

A manager is a gatekeeper or change agent who filters messages as they come over channel, controls which messages are passed along the channels and determines the most effective method of presenting them. According to Berkhard (1969), the manager plays the following roles:

- Managers are continually working on the problems of how to develop a flexible organization which can move with changing requirements, which can be proactive (influencing the environment) rather than reactive

- Managers are seeking ways to establish a research climate in which increasing complex decision can be made by people with the information regardless of their location in the organization

- Managers are looking for ways in which new and complex technologies can be managed and in which people who have an ever higher sense of freedom and autonomy can be encouraged to want to stay and work in their organization

\section{CONCLUSION}

Every organization has a culture and this culture can be managed for effective communication. Surely, an organization cannot exist without communication and it has also been advanced that an organization is as good as its communication system.

Therefore, having utilized the necessary strategy for the planning of a better organization's culture management, it is expected that effective communication will be evolved. An effective communication invariably 
means goal-directed communication which should ensure the realization of the organizational goals and objectives.

\section{REFERENCES}

Allen, R.K., 1977. Organizational Management through Communication. Harper and Row Publishers, New York.

Bantz, C.R., 1993. Understanding Organization: Interpreting Organizational Communication Cultures. University of South Carolina Press, Columbia, SC.

Barnett, G.A., 1988. Communication and Organizational Culture. In: Handbook of Organizational Communication, Goldhaber, G. and G.A. Barnett (Eds.). HJ Ablex, Norwood.

Beckhard, R. and W. Pritchard, 1992. Changing the Essence: The Art of Creating and Leading Fundamental Change in Organization. Jossey-Bass Inc., San Francisco CA.

Beckhard, R., 1969. Organizational Development: Strategies and Models. Addison-Wesley Co. Inc., New York.

Carr, D.K, K.J. Hard and W.J. Trahant, 1996. Managing the Change Process. McGraw-Hill Inc., New York.

Corad, C., 1994. Strategic Organizational Communication: Towards the Twenty-First Century. 3rd Edn., Harcourt brace College Publisher, Forth. Worth.

De Witt, R., 2004. Managing change is managing people. http://www.cioupdate.com/insights/article.php/110 49_3348041_1/Managing-Change-Is-ManagingPeople.htm.

Jeffres, L.W., D.J. Atkin, C.C. Bracken and Neuendorf, 2004. Cosmopoliteness in the internet age. J. Comput. Med. Commun., Vol. 10, No. 1.

Kast, F.E. and J.E. Rosenzweig, 1974. Organization and Management: A Systems Approach. Phoenix Press Inc., Philippines.
Kolawole, C.O. and J.A. Akinyele, 2002. Communication Skills for Corporate Managers. Media Konsult, Ibadan.

Maurus, J., 1996. The Act of Communicating Effectively. Better Yourself Books, Bandra, Mumbai.

McQuail, D., 2005. McQuail's Mass Communication Theory. SAGE Publications Ltd., London.

National Defence University, 2006. Strategic leadership and decision making. Part Five: Analysing Organization. http:/www.au.af.mil/au/awc/awcgate/ ndu/strat-ldr-dm/pt5ch20.html.

Nellen, T., 1997. Organizational culture and leadership. http://www.tnellen.com/ted/tc/schein.html.

Pepper, G.L., 1995. Communication in Organizations: A Cultural Approach. McGraw-Hill Inc., Singapore.

Sathe, V., 1983. Implication of corporate culture: A managers guide to action. Organ. Dyn., 12: 4-23.

Smircich, L., 1985. Is the Concept of Culture a Paradigm for Understanding Organizations and Ourselves? In: Organizational Culture, Frost, P.J., L.F. Moore, M.R. Lousia, C.C. Lundberg and J. Martin (Eds.). SAGE Publications, Beverly Hills, pp: 55-72.

Soola, E.O. and O.O. Ayoade, 2000. Organizations: Nature, Structure, Types and Communication. In: Organizational Communication: A Book of Reading, Soola, E.O. (Ed.). Delby Concept, Ibadan.

Soola, E.O., 2000. Organizations as Routinized, Yet Dynamic Entities. In: Organizational Communication: A Book of Reading, Soola, E.O. (Ed.). Delby Concept, Ibadan, pp: 1-9.

The Institute for Working Futures, 2005. Interpersonal personal skill. http://www.marcbowles.com/ifwf/.

Timony, B., 2001. The role of organization development in large-scale organizational change. http://www. newfoundations.com/Org Theory/Timony 721 .html. 